\title{
Using a developed PM in order to optimize the production productivity in a cement industry
}

\author{
$1^{1 *}$ NAGHILOO, A; ${ }^{2}$ FARZANEH, $H ;{ }^{3}$ SHAHABI, H R; ${ }^{4}$ ASSADI, M KH; ${ }^{5}$ DASHTI, M \\ 1,2,4,5 Department of Energy Engineering, Graduate School of Environment and Energy, Science and Research Campus ,Islamic Azad University, \\ Tehran, Iran \\ ${ }^{3}$ Department of Industrial Engineering, Amirkabir University of Technology, 424 Hafez Ave., Tehran, Iran
}

\begin{abstract}
Cement factories are highly energy and cost intensive industries. Producing the cement requires a lot of energy to transform the raw material into final product. One major area to improve the production productivity is preventive maintenance (PM). It helps to protect assets, increase the useful life of equipment, improve system reliability, decrease cost of replacement and finally improve system energy consumption.

In this paper, the theory of microeconomics firm was used to find a model of optimal production productivity in cement industry. To show the effect of preventive maintenance system in the model, energy consumption of equipment is considered as a function of failure rate of equipment and then added to the set of constraints. Using this model energy consumption is reduced up to $15 \%$ and total annual cost is reduced up to $12.7 \%$.
\end{abstract}

Keywords: Preventive maintenance (PM), Energy saving, Cement industry, Production productivity

Cement factories are highly energy and cost intensive industries, and energy cost is $30-40 \%$ of the total production cost (Szabo et al,2003). Clinker producing include the following operations: preheating the raw material, precalcination, burning inside the kiln and clinker cooling (Sattari and Avami,2007).In a typical cement plant, pyroprocessing unit is thermal energy intensive and accounts for about $90 \%$ of the thermal energy used in cements production process (Holderbank Inc,1993). Assessing the thermal performance of cement industries fuel consumption is a major commodity to study (Worell et al,2000; Liu et al,1995).An appropriate method for thermal performance analysis must be adopted to achieve the principal objectives, such as maximizing the plant productivity, minimizing the raw material, minimizing the energy consumption of any cement industry. The objectives could be achieved by reducing the energy consumption of the plant that it means a search for energy efficiency leading to a productivity improvement (Rasul and Widianto,2005).

Production planning models seek typically to balance the costs of setting up the system with the costs of production and materials holding, while maintenance models attempt typically to balance the costs and benefits of maintenance plans in order to optimize the performance of the production system. In both domains, issues of production modeling and maintenance modeling have experienced an evident success both from theoretical and applied viewpoints. Paradoxically the issue of combining production and maintenance plans has received much less attention. The large part of the production planning models assumes that the system will work at its maximum performance during the planning horizon, and the large part of the maintenance planning models disregards the impact of maintenance on the production capacity and does not explicitly consider the production requirements. Actually, apart from the preventive maintenance actions that can be scheduled during down times, any unplanned maintenance action disturbs the production plan. It is therefore crucial that both production and maintenance aspects related to a production system are concurrently considered during the elaboration of optimal production and maintenance plans (Aghezzaf et al,2007).

Aghezzaf et al (2007) proposed an integrated production and preventive maintenance planning model. The main objective of this model was to determine an integrated production and maintenance plan to minimize the expected total production and maintenance costs over a finite planning horizon. The model takes into account the fact that the production system may fail randomly. In fact Aghezzaf et al's model takes explicitly into consideration the reliability parameters of the system. Considering the reliability parameters, PM cost is entered as a function of failure rate in their model. Suitable equipment maintenance can improve the reliability of the production system (Richard et al,2000) and higher plant reliability leads to reduce the frequency of equipment failure and waste of energy (Eti et al,2006). Therefore PM can reduce energy consumption based on increasing reliability.

In this paper, the effect of failure rate on energy consumption and total production costs are investigated using PM cost of Aghezzaf et al's model. Also, the model of optimal production productivity in cement 
Using a developed PM in order.....

industry has been founded on the theory of firm in microeconomics. Based on this theory, the cement factory owner can improve production productivity based on minimizing the total cost of the system to satisfy the required production demand and technological, economical, environmental constraints. To show the effect of preventive maintenance system in the model, energy consumption of equipment is considered as a function of failure rate of equipment and then added to the set of constraints. In this work the aforementioned model has been developed using the techniques of mathematical programming. The model depicts the behavior of a non-linear system and includes some non linear functions in the objective function and in the constraints. Solution the large non linear set of constraints and identifying the global optimal energy flow is a major issue in process of developing the model. Therefore, an integrated approach based on numerical analysis and the concept of control volume has been developed and applied to solve the model. The approach and the application of the model demonstrated using a case study (Ouromieh cement factory in Iran). The implementation of the model leads to the realization of energy saving potential that is considerable.

\section{MATERIALS AND METHODS}

The economic rationality of producer and activity of a firm has extensively been developed as a branch of micro economics and it has been utilized to explain the development of production technology. It is stated that a firm strives towards establishing a system of production and delivery with minimum costs subject to satisfying the demand and other technical, economical and institutional constraints (Saboohi,2000). This concept formulated as below:

$$
\operatorname{Min} z=P X
$$

subject to:

$f\left(x_{1}, x_{2}, \ldots, x_{n}\right) \geq Q$

$\mathrm{x}_{1}, \mathrm{x}_{2}, \ldots, \mathrm{x}_{\mathrm{n}} \geq 0$

Where:

Z: Total production cost

P: Vector of production factor prices

$\mathrm{X}$ : Vector of the range of using sources

$\mathrm{Q}$ : The range of product that should be produced

At mentioned model, total production cost is minimized. Total production cost of the cement factory including fuel, material, labor and PM cost is depicted by $\mathrm{z}$ as objective function of the system. Therefore, total production cost of cement factory is shown as follow:

Total cost $=\left(\mathbb{E}_{\mathrm{T}} \times \mathbb{P}_{\mathrm{E}}\right)+\left(\mathrm{M}_{\mathrm{i}} \times \mathrm{P}_{\mathrm{m}}\right)+\mathrm{P} \mathrm{M}_{\mathrm{C}}+\mathrm{N}$

Where:

$\mathbb{E}_{\mathrm{T}}=$ Total fuel consumption

$\mathbb{P}_{\mathrm{E}}=$ Unit price of fuel
$M_{3}=$ Raw material weight

$\mathbf{P}_{\mathrm{m}}=$ Unit price of material

$\mathbf{P M}_{\mathrm{C}}=$ Preventive cost of factory

$\mathrm{N}=$ Labor cost

PM cost is (Aghezzaf et al,2007):

$\mathrm{PM}_{\mathrm{C}}=\frac{\mathrm{m}}{\mathrm{T}}\left(\mathrm{C}_{\mathrm{p}}+\mathrm{C}_{\mathrm{r}} \int_{0}^{\mathrm{T}} \mathrm{r}(\mathrm{t}) \mathrm{dt}\right)$

Where:

T: Duration of preventive maintenance cycle (monthly)

$\tau$ : Duration of each basic planning period (daily)

$\mathrm{n}$ : The number of fixed length $\tau$

$\mathrm{CP}$ : Cost of each preventive maintenance during cycle.

$\mathrm{Cr}$ : Cost to carry out a corrective maintenance action $\left(\mathrm{C}_{\mathrm{p}} \leq \mathrm{C}_{\mathrm{T}}\right)$

$\mathrm{r}(\mathrm{t})$ : Failure rate of system

Fuel consumption from required enthalpy for clinker formation :In cement industry, the main compounds including $\mathrm{CaCO}_{2}, \mathrm{SiO}_{2}, \mathrm{Fe}_{2} \mathrm{O}_{3}$ and clay, in addition to creating four main minerals of cement (cement clinker phases), create the following products, i.e. final products (Labahn,1983).

1. C $\mathrm{S}$ (Alite)

2. $C_{2} S$ (Belite)

3. $\mathrm{C}_{7} \mathrm{~A}$

4. $\mathrm{C}_{2} \mathrm{AF}$

Baking process in cement kilns are classified as follows:

1. Dehumidifying clay minerals

2. Analyzing calcium carbonate and magnesium (calcinations)

3. Solid phase reactions

4. Liquid phase reactions

5. Crystallization processes

Each process should be done using a minimum energy at the shortest time, thus it is necessary to cyanotic of each of them. Mechanism of gaining total required thermal energy of rotary kiln is as follows:

First rotary kiln is divided into two areas which most chemical reactions are done there. Then through total enthalpies of two areas, we can gain total optimum thermal energy required by main phases of cement clinker. In this work the effect of reactions contained inconsiderable enthalpies were ignored.

Rotary kiln is divided into two main areas of forming clinker phases as follows:

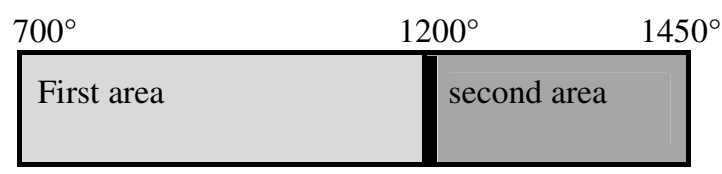


Using a developed PM in order.....

The first area includes precalciner and the starting section of kiln which calcinations a thermal reaction with the highest enthalpy.

$\mathrm{CaCO}_{2} \rightarrow \mathrm{CaO}+\mathrm{CO}_{2}$

Raw materials into kiln:

feed $=209.125 \times 10^{2} \mathrm{~kg} / \mathrm{hr}$

Product (clinker) from rotary kiln:

product $=119.625 \times 10^{\mathrm{a}} \mathrm{kg} / \mathrm{hr}$

Total enthalpies in first area:

$\Delta \mathrm{H}_{1}=78422578.8 \mathrm{kcal} / \mathrm{hr}$

Second area includes main reactions of forming cement clinker phases (Labahn,1983).

$2 \mathrm{cao}+\mathrm{sio}_{2} \rightarrow 2 \mathrm{crosio}_{2}$

$2 \mathrm{caOsio}_{2}+\mathrm{caO}-3 \mathrm{caosio}_{2}$

$3 \mathrm{caO}+\mathrm{\alpha Al}_{2} \mathrm{O}_{2} \rightarrow 3 \mathrm{caOAl}_{2} \mathrm{O}_{2}$

$4 \mathrm{cao}+\alpha \mathrm{Al}_{2} \mathrm{O}_{2}+\alpha \mathrm{Fe}_{2} \mathrm{O}_{3} \rightarrow 4 \mathrm{caoAl}_{2} \mathrm{O}_{2} \mathrm{Fe}_{2} \mathrm{O}_{3}$

Total enthalpy of second area to perform the reactions in this area is

$\Delta \mathrm{H}_{2}=-35486115 \mathrm{kcal} / \mathrm{hr}$

Therefore total enthalpies of first and second area will gain necessary total thermal energy for performing reactions and forming clinker:

$\Delta \mathrm{H}_{1}-\Delta \mathrm{H}_{2}=74873967.3 \mathrm{kcal} / \mathrm{hr}$

$119.625 \times 10^{2} \frac{\mathrm{kg}}{\mathrm{hr}} \times \Delta \mathrm{H}=74873967.3 \frac{\mathrm{kcal}}{\mathrm{hr}} \rightarrow$
$\Delta \mathrm{H}=625.9 \frac{\mathrm{kcal}}{\mathrm{kg}}=0.0026 \frac{\mathrm{Gj}}{\mathrm{kg}}$

Fuel mass consumption of factory can be gained from following equations because above value is required enthalpy for clinker formation.

$m_{\text {out }} \times \Delta \mathrm{H}=\mathrm{m}_{\mathrm{f}} \times \mathrm{NCV}$

$\mathrm{m}_{\mathrm{f}}=\frac{\mathrm{m}_{\mathrm{sut}} \mathrm{rov0026}}{\mathrm{NCV}}$

$\mathrm{NCV}=$ Net Calorific Heat Value of fuel $(\mathrm{GJ} / \mathrm{kg})$

$\mathrm{m}_{\text {out }}=$ Mass of produced clinker $(\mathrm{kg})$

Effect of produced product (clinker) on electrical energy consumption in kiln department: The range of electrical energy consumption of kiln department of Oroumieh cement factory is \%20.9 of total consumed electrical energy of factory (Malkham,2008). Therefore, in this paper, it has tried to gain the relation between produced clinker of kiln unit and consumed electricity of this unit through regression.

Mathematical relation between produced clinker kilogram ( $\mathbf{m}_{\text {out }}$ ) and consumption of electrical energy of kiln department $\left(\mathbb{E}_{\mathbf{E}}\right)$ can be shown in a graph. Using the records, the range of consumed electrical energy and the range of produced clinker at kiln unit of Oroumieh cement factory, is shown in Fig.1.

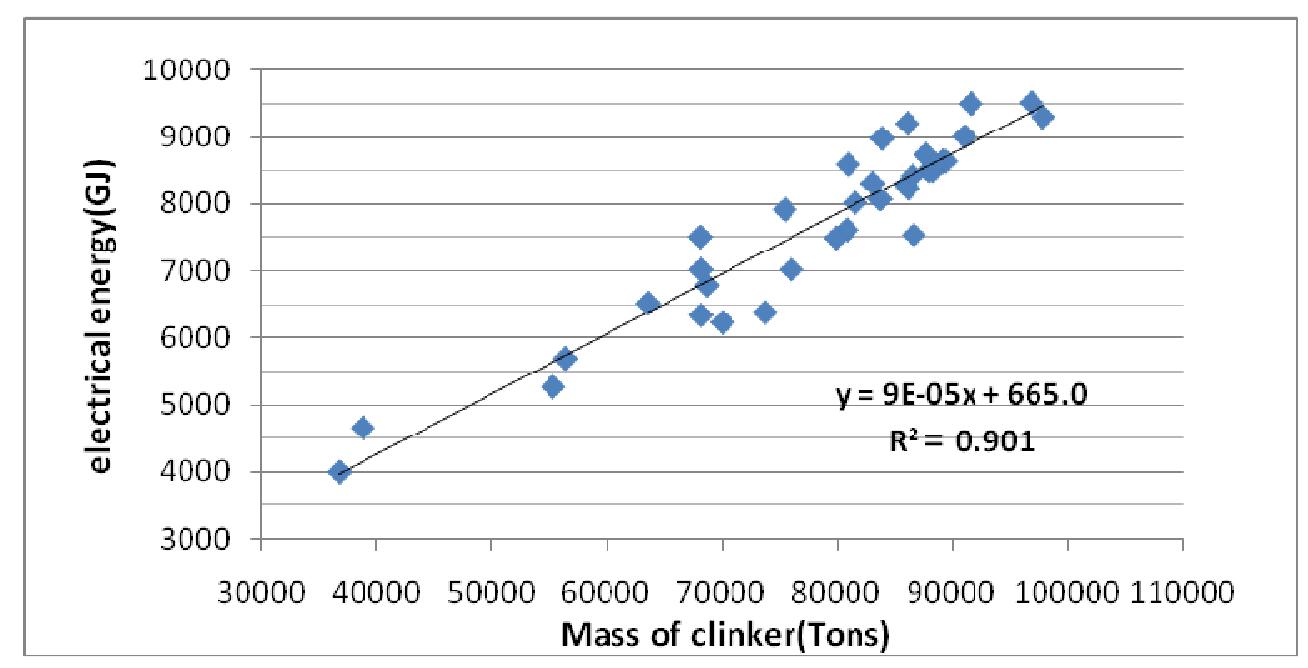

Fig.1. Mathematical relation between consumption of electrical energy of kiln department (GJ) and mass of clinker (Tons)

Therefore

$\mathbf{E}_{\mathrm{e}}=9 \times 10^{-5} \mathrm{~m}_{\text {vut }}+665$
Determine of total consumed energy limitation $\left(E_{t}\right)$ in kiln department: Based on records net thermal value of fuel oil is $9844.6 \mathrm{kcal} / \mathrm{kg}$, thus:

$$
9844.6 \frac{\mathrm{Kcal}}{\mathrm{Kg}} \times 4.18 \times 10^{-6}=0.04115 \frac{\mathrm{G}}{\mathrm{Kg}}
$$


Using a developed PM in order.....

NCV of fuel oil which is consumed fuel of Oromieh cement factory is $0.04115 \mathrm{GJ} / \mathrm{kg}$.

Total consumed energy at kiln department is the total of fuel oil and electrical energies. Therefore, total consumed energy of oven unit $\boldsymbol{E}_{\mathrm{t}}$ is as follows:

$E_{T}=\left(m_{E} \times 0.04115\right)+E_{E}$

$\mathrm{m}_{\mathrm{f}}: \mathrm{Kg}$ fuel oil of kiln department

Effect of $r(t)$ on total energy consumption $\left(\boldsymbol{E}_{T}\right)$ in kiln department: Machineries failure is a random variable and its occurrence time is not distinct. Abundance of failure and its occurrence time is random and eventual variable that it's distributive subsidiary is determined using statistical distributions. It is assumed that the failure probability density function $f(t)$ and the cumulative distribution function $\mathbf{F}(\mathrm{t})$ of the production system are known. We let $r(t)$ to be failure rate of a system at the time $t$. It is well known that $r(t)$ is given by (Aghezzaf et al,2007):

$\mathrm{r}(\mathrm{t})=\frac{\mathrm{f}(\mathrm{t})}{1-\mathrm{E}(\mathrm{t})}$

We should consider to prepare the term of distribution function from the histogram by the number of failure and the operation time. Since we want to calculate the relation between failure rate and energy, we need the proportioned number of failures with energy and operation time.

(18)
Energy consumption (E) depends on both number of failure $(\mathrm{N})$ (for example, the compressor which uses a lot of energy for each time getting started) and the operation time $(\mathrm{t})$. If we only consider the number of failure, in this case the operation time that is effective on energy consumption will be neglected. For instance, if we have 20 times stop for 10 minutes in one month, and in the next month we have 10 times stop for over one hour, we have only considered that 20 times stops more than 10 times stops and we have not considered the operation time. Gaining histogram of failure distribution needs the number of failure. On the other hand, we want to consider the relation of failure rate and energy consumption, thus we should enter the proportion coefficient $(\alpha)$ between energy consumption and number of failures at once. Fig.2. shows relation between operation time and energy consumption (GJ) and Fig.3.shows relation between operation time and number of failures. The details are as follow:

$\left\{\begin{array}{l}E=f(N, t) \\ E_{t}=f\left(N_{t}\right)\end{array} \Rightarrow E_{t} \alpha N_{t} \Rightarrow a=\frac{E_{t}}{N_{t}}\right.$

And

$\left\{\begin{array}{c}E=f(N, t) \\ r(t)=f(N, t)\end{array} \quad \Rightarrow E_{t}=f(r(t))\right.$

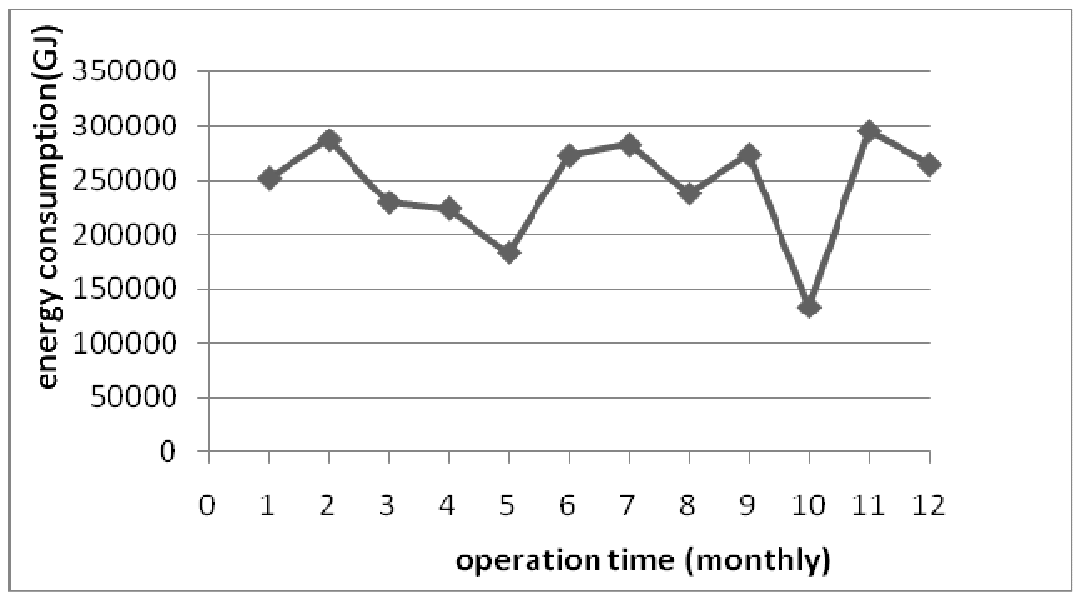

Fig.2.Relation between operation time (monthly) and energy consumption (GJ) 
Using a developed PM in order.....

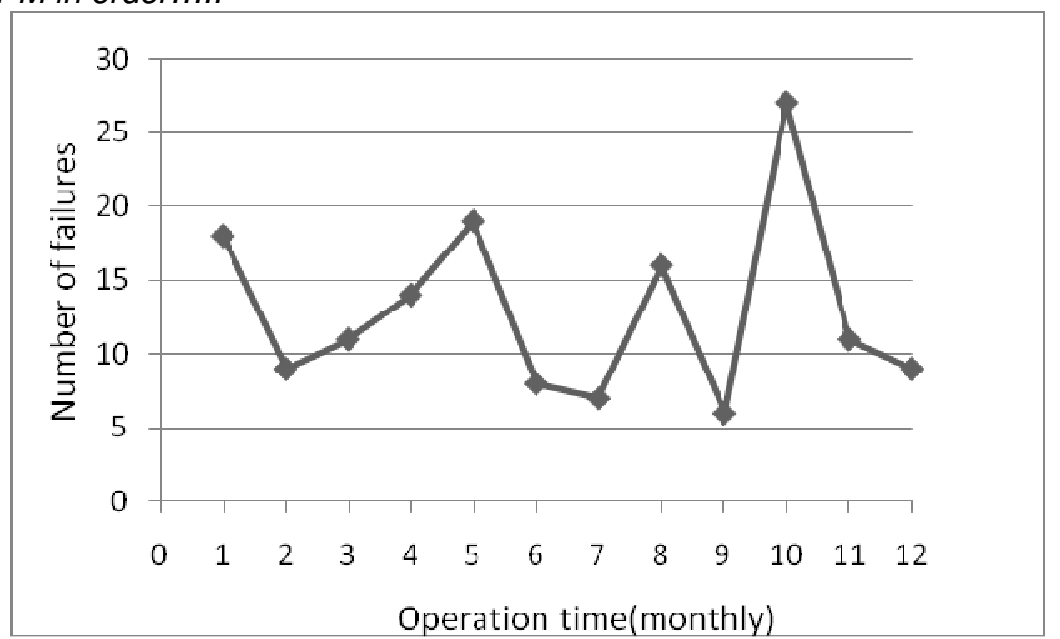

Fig.3.Relation between operation time (monthly) and number of failures

Finally, by considering this proportion coefficient for number of failure, using the Arena software the failure distribution of factory is gained uniform distribution. For uniform distribution failure rate is

$$
r(t)=\frac{1}{b-t}
$$

where: $b$ is operation time of kiln department annually and $\mathrm{t}$ is operation time of preventive maintenance cycle.
Mathematical relation between failure rate and total energy consumption of kiln department (GJ) is gained through regression which is applied as one of the restrictions in production productivity model as shown in Fig.4.

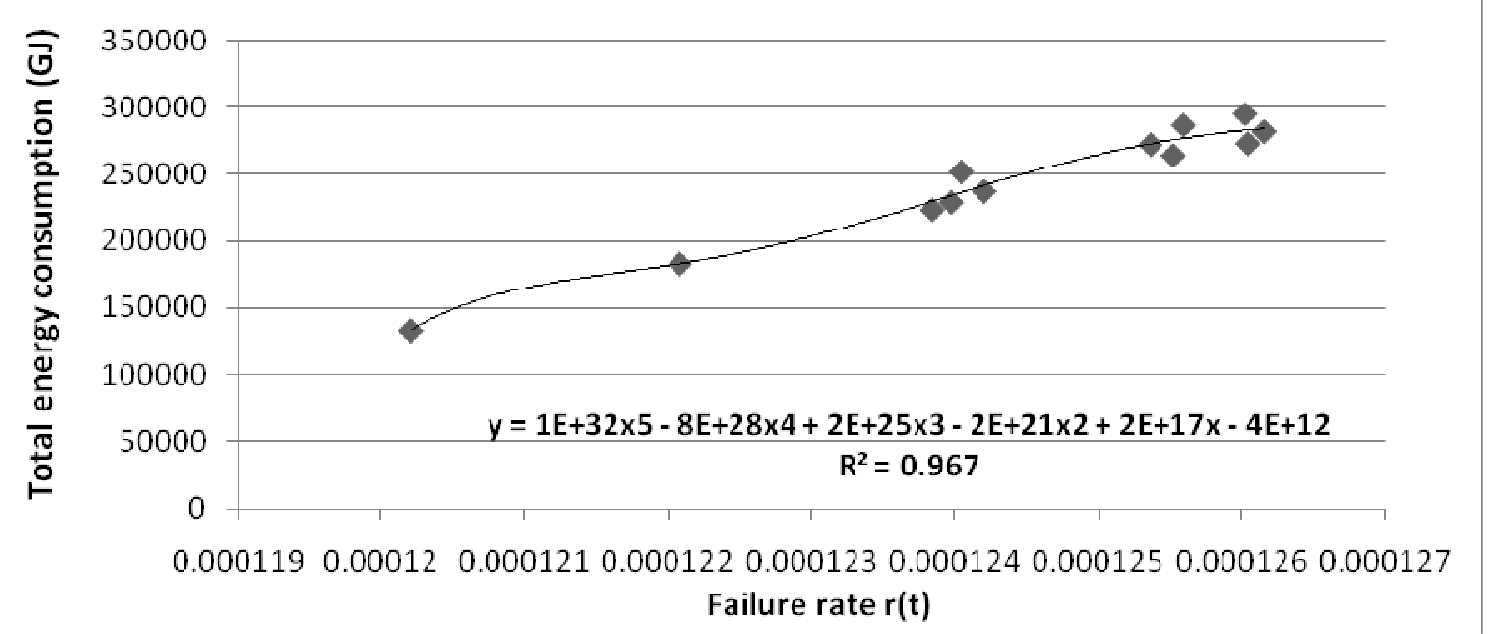

Fig.4. Mathematical relation between total energy consumption (GJ) and failure rate $r(t)$

Therefore 
Using a developed $P M$ in order.....

$$
\mathrm{E}_{\mathrm{T}}=1 \mathrm{E}+32 \mathrm{r}^{5}-8 \mathrm{E}+28 \mathrm{r}^{4}+2 \mathrm{E}+25 \mathrm{r}^{3} \mathrm{x}
$$$$
-2 \mathrm{E}+21 \mathrm{r}^{2}+2 \mathrm{E}+17 \mathrm{r}-4 \mathrm{E}+12
$$

Where $r$ is failure rate.

Physical Constraint of mass flow: Mass flow in each system is limited by technical capacity. Mean while mass of raw material in the system is not more than capacity designed. Ouromieh cement factory physical constraint for mass flow is followed (Malkham,2008):

$\mathrm{M}_{\text {in }}=1.748 \mathrm{~m}_{\text {out }}$

Mathematical model of production productivity: Total cost of cement factory (including fuel, material, labor and PM cost) is depicted by $\mathrm{z}$ as objective function of the system. Therefore, total production cost of cement factory is:

$$
\mathrm{Z}=\left(\mathrm{E}_{\mathrm{T}} \times \mathbb{P}_{\mathrm{E}}\right)+\left(\mathrm{M}_{\mathrm{i}} \times \mathbb{P}_{\mathrm{m}}\right)+\mathrm{PM}_{\mathrm{C}}+\mathrm{N}
$$

Therefore, production productivity model and its constraints are as follows:

$$
\operatorname{Min}_{\left(\mathrm{M}_{\mathrm{i}} \times \mathrm{P}_{\mathrm{m}}\right)+\left(\mathrm{C}_{\mathrm{p}}+\left(\mathrm{C}_{\mathrm{r}} \times \mathrm{T} \times \mathrm{r}\right)\right)+\mathrm{N}}\left(\mathbb{E}_{\mathrm{T}} \times \mathbb{P}_{\mathrm{E}}\right)+
$$

(23)

Subject to constraints:

$$
\mathrm{m}_{\mathrm{f}}=\frac{\mathrm{m}_{\mathrm{sut}} \times 24 \mathrm{~B} \times 10^{-\mathrm{B}}}{\mathrm{N} \mathrm{CV}_{\mathrm{V}}}
$$

$$
\begin{aligned}
& E_{E_{i}}=9 \times 10^{-5} m_{\text {vut }}+665 \\
& E_{T^{T}}=\left(m_{\mathrm{f}} \times 0.04115\right)+E_{E} \\
& E_{T}=1 \mathrm{E}+32 \mathrm{r}^{5}-8 \mathrm{E}+28 \mathrm{r}^{4}+2 \mathrm{E}+25 \mathrm{r}^{3} \times \\
& -2 \mathrm{E}+21 \mathrm{r}^{2}+2 \mathrm{E}+17 \mathrm{r}-4 \mathrm{E}+12 \\
& \mathrm{M}_{\text {in }}=1.748 \mathrm{~m}_{\text {cut }}
\end{aligned}
$$

\section{RESULTS AND DISCUSION}

Based on production productivity model, using GAMS software for $112554250 \mathrm{~kg}\left(\mathrm{M}_{\mathrm{in}}\right)$, the optimum extent of failure rate is 0.000025 that compare to 0.000125 i.e. average failure rate on the base of real condition of factory has a lower extent. This means that the failure rate for the cement factory in optimum status is less than average extent in work time of factory. Also optimum extents of monthly consumed energy and monthly total production cost for kiln department are gained 226030GJ and MRials 3661 respectively.

Table 1.shows the results of different status of failure rate for rotary kiln department annually (optimum failure rate and average of real failure rate of cement factory).The extent of annual final product is 772683.6 ton.

Table1. Comparison between real and optimum condition

\begin{tabular}{|c|c|c|c|c|c|c|}
\hline $\begin{array}{c}\text { Total cost } \\
\text { of kiln } \\
\text { department } \\
(\mathrm{M} \$ \text { /year) }\end{array}$ & $\begin{array}{c}\text { cost of } \\
\text { energy(M\$year) }\end{array}$ & $\begin{array}{c}\text { cost of energy } \\
\text { (MRials/year) }\end{array}$ & $\begin{array}{c}\text { Consumed } \\
\text { energy for each } \\
\text { tone of } \\
\text { product(GJ/t) }\end{array}$ & $\begin{array}{c}\text { PM } \\
\text { costs(M\$/year) }\end{array}$ & $\begin{array}{c}\text { failure } \\
\text { rate }\end{array}$ & Status \\
\hline 26.7 & 22.7 & 4547.2 & 4.14 & 0.13 & 0.000125 & $\begin{array}{c}\text { Real } \\
\text { condition }\end{array}$ \\
\hline 23.3 & 19.3 & 3854.3 & 3.51 & 0.09 & 0.000025 & $\begin{array}{c}\text { Optimum } \\
\text { condition }\end{array}$ \\
\hline
\end{tabular}

Table 1.shows that reducing the failure rate to 0.000025 i.e. optimizes status of failure rate and makes optimum the production productivity. Therefore the following results based on this work are accessible. 1- Overtaking optimum failure rate reduces PM costs annually about $31 \%$ i.e. $\mathrm{M} \$ 0.04$.

2- Annual consumed energy for each tone of product reduces $0.6 \mathrm{GJ} / \mathrm{t}$ and reaches to $3.5 \mathrm{GJ} / \mathrm{t}$ (about $15 \%$ ).

3- Annual energy cost, by accounting Iranian Currency, at real condition of factory is about MRials 4547.2 and in optimum status, it reaches to MRials 3854.3 (the range of saving is 692.9 MRials/year).
4- Energy annual cost, by accounting international prices, at present situation of factory is $\mathrm{M} \$ 22.7$ and in optimum status, it is about $\mathrm{M} \$ 19.3$ i.e. about $15 \%$ reduction.

5- Total annual costs of kiln department at real condition is $\mathrm{M} \$ 26.7$ and in optimum status, it reaches to M\$23.3 (about 12.7\%).

According to the parameters affecting the energy loss in rotary kiln Department, following maintenance strategies are recommended. 
Using a developed PM in order.....

(i) Rotary kiln inspection to set performance DC motor rotation and optimization speed baking materials in the kiln.

(ii) Performing preventive maintenance for controlling combustion and optimum fuel to air ratio.

(iii) Inspection the performance of Greet cooler fans.

Therefore it is recommended to implement PM properly,(short and long term scheduled maintenance programs ).

Conclusion: In this paper, the theory of microeconomics firm was used to find a model of optimal production productivity in cement industry. According to this work the failure rate of Ourmieh cement factory can be reduced from 0.000125 to 0.000025.Therefore using this method can reduce the annual energy consumption and total production cost up to $15 \%$ and $12.7 \%$ respectively. The results show that the reduction extent in energy costs, accounting international prices, is more than the extent of Rials reduction of energy and it is due to unreal price of energy in Iran. Actually the Iranian government pays subsidy for energy thus the managers not willing to employ energy saving strategies. Since in this paper, the results of decreasing the failure rate are significant, the preventive maintenance (PM) role is important.

In this paper uniform distribution was used for failures. In future work can use stochastic model to study on effect of failure rate on energy consumption and total production cost. Also the failure rate function and $\mathrm{co}_{2}$ emission can consider as a constraint and $\mathrm{CO}_{2}$ emission costs can use as factory costs in the objective function in future work.

\section{REFERENCES}

Aghezzaf, E H;Jamali,M A; Ait-Kadi,D(2007).An integrated production and preventive maintenance planning model. European Journal of Operational Research 181: 679-685.

Eti,M C; Ogaji,S O T;Probert,S D(2006). Development and implementation of preventive-maintenance practices in Nigerian industries. Applied Energy 83:1163-1179.
Holderbank Inc(1993). Heat balance of kiln and coolers and related topics, Cement seminar: comminution engineering, process technology.

Liu,F; Ross,M; Wang,S(1995). Energy efficiency of Chinas cement industry, Energy 20 (7); 669-689.

Labahn, O; Khlhaas, B(1983).Cement Engineer's Handbook,Bauverlag.

Malkham,m(2008).Electrical auditing of Ourmieh cement factory research, Fars and Khozestan engineering cement industry company ,112-113.

Rasul , M G; Widianto,W(2005). Assessment of the thermal performance and energy conservation opportunities of a cement industry in Indonesia, Applied Thermal Engineering 25: 2950-2965.

Richard, C M; Peter Tse; Li Ling; Francis Fung (2000). Enhancement of maintenance management through benchmarking, Journal of Quality in Maintenance Engineering, Vol. 6 Iss: 4, pp.224 - 240.

Saboohi ,Y(2000).Energy flow optimization model in industries, Sharif Energy Research Institute.

Sattari, S; Avami, A(2007). Assessment of energy saving opportunities of cement industries of Iran: 3rd

IASME WISEAS International Conference on Energy, Environment, Ecosystem and Sustainable Development, Agios Nikoaous, Greece: p. 585593.

Szabo,L; Hidalgo,I; Ciscar, J C; Soria, A; Russ, $\mathrm{P}(2003)$. Energy consumption and $\mathrm{CO} 2$ emissions from the world cement industry, European Commission Joint Research Centre. Report EUR $20769 \mathrm{EN}$.

Worell, E; Martin,N; Pryce,L(2000). Potentials for energy efficiency improvements in the US cement industry, Ener 